\title{
RETHINKING FUNCTIONAL PARAMETRIZATION: A VIEW FROM HONORIFICATION IN THE NOMINAL DOMAIN IN JAPANESE
}

\author{
HIROMU SAKAI and ADRIAN IVANA \\ Hiroshima University and Livegraphy Laboratories Limited
}

\begin{abstract}
Research on Japanese-English comparative syntax has argued that the Japanese-type languages lack functional categories. Nevetheless, certain syntactic phenomena in Japanese have often been argued to support intricate phrase architecture with multiple layers of functional projections as assumed in the English-type languages. Faced with this apparent contradiction, this paper rethinks the role of functional categories in the theory of parameters from the viewpoint of honorification in the nominal domain in Japanese. The result shows that parametric variation between the two types of languages should be attributed to a more fine-grained difference as to how categories with lexical content are integrated into their syntactic computation.*
\end{abstract}

Keywords: comparative syntax, agreement, noun phrase, honorification

\section{Introduction}

A series of influential studies on the nature of parameters of Universal Grammar in the 1980s (Borer (1984), Fukui (1986), among others) set a productive research framework by assuming that possible range of parameters is narrowly restricted in the domain of functional categories. Subse-

* This research was supported by the Japan Society for the Promotion of Science Grant-in-Aid for Scientific Research (\#20320060), the Japanese Ministry of Education, Culture, Sports Science \& Technology Grant-in-Aid for Scientific Research on Priority Areas-System Study on Higher-Order Brain Functions-(\#20020020), and the Japan Promotion for Science \& Technology RISTEX Brain Science and Education Research Development Program Type II (PI, Hiroko Hagiwara, Tokyo Metropolitan University).

The contents of this research were presented at the symposium entitled "The Emergence of Functional Categories from a Cross-Linguistic Perspective" at the 26th Conference of the English Linguistics Society of Japan held at University of Tsukuba. We appreciate the comments and suggestions from the audience. We are also grateful to Rosalynn S. Chiu for English language proofreading and the anonymous reviewers of English Linguistics for their valuable suggestions for improvement. Any remaining errors and inadequacies are ours.

English Linguistics 26: 2 (2009) 437-459 -437-

(C) 2009 by the English Linguistic Society of Japan 
quent development (Fukui (1986, 1995), Fukui and Sakai (2003)) revealed that properties of functional categories vary in a substantial way from language to language, and that human languages of a certain type, let us call them the Japanese-type languages, lack functional categories strictly defined by a set of characteristics found in the English-type languages (Abney (1987)). At the same time, Koizumi (2000) and Kishimoto (2001) found that the Japanese language has an abstract functional projection of $v \mathrm{P}$. Watanabe $(2006,2008)$ proposed that the Japanese noun phrases have functional projections of DP and NumP. This paper rethinks the role of functional categories in the theory of parameters in order to reconcile these apparently contradictory views, and argues that the difference should be attributed to a more fine-grained difference between lexical as well as functional categories. To provide empirical support for this claim, we examine honorification phenomena in Japanese.

Up to the present, extensive research was conducted on honorific constructions in the verbal domain in Japanese (Harada (1976), Suzuki (1989), Toribio (1990), to name a few). Although those honorification studies have achieved one of the most productive and successful results in the field of Japanese generative linguistics, honorification in the nominal domain has never attracted enough attention.
(1) sensei-no go-kazoku
Professor-Gen Hon-family
'the Professor's family'
(2) *watashi-no go-kazoku
I-Gen Hon-family
'my family'

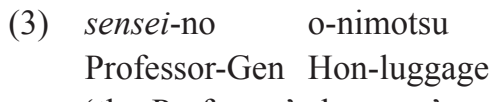
(4) *watashi-no o-nimotsu
I-Gen Hon-luggage
'my luggage'

In these examples, the honorific prefix o-/go- can be used when the possessor noun is respected, while it is totally unacceptable for a non-respected possessor. $^{1,2}$ This means that, unlike much of the previous literature, we

1 The honorific prefix is unique, but has two phonetic forms. The $o$ - form is used when attached to the so-called wago (native Japanese words), such as o-kuruma 'car,' 
have to deal with honorification within the nominal domain in the absence of the so-called honorific verbs.

To present a unified analysis of Japanese nominal honorific expressions, we should answer the following questions, namely, (i) how honorification can be achieved in the absence of verbs, (ii) why nominal honorific expressions should be distinguished from non-honorific expressions with the prefix o-/go- and how this can be achieved, and (iii) how the target of honorification can be identified within the nominal domain. These questions can be solved by a general theory of feature-checking coupled with a hypothesis of rich internal architecture of noun phrases.

Our analysis argue for Watanabe $(2006,2008)$ and others' view that Japanese noun phrases consist of multiple 'NP-shell' projections, and Kishimoto's (1996) and Boeckx and Niinuma's (2004) view that feature-checking is relevant to the determination of the target of honorification. At the same time, neither the syntactic categories which project to form the NPshell structures nor the features which enter into the checking processes are purely 'functional' according to the original definition (Fukui (1986), Abney (1987)), since they clearly have semantic or pragmatic contents. These considerations lead us to conclude that categories with lexical content can be integrated into the syntactic computation of the Japanese language and that reconsideration of the functional parametrization hypothesis is necessary to acount for the parametric variation among human languages.

\section{Some Previous Approaches to Honorification}

In this section we briefly mention some important approaches to honorific expressions. Almost all of them consider the existence of so-called honorific verbs suru 'make' and naru 'become' essential to the honorific meaning. We first look at approaches that do not assume agreement as the

while the go- form is used with kango (Sino-Japanese words), such as go-kekkon 'wedding.'

${ }^{2}$ We use here the term respected in the sense that the designated person is respected in the context of the utterance. The context of the utterance is sometimes difficult to identify, as it includes considerations such as the relative social status of the speaker, hearer and even overhearer, the relative social status of the referents of the utterance and perhaps even the physical environment of the utterance. Although the identification process clearly involves pragmatic or sociolinguistic factors, we follow the idea that the honorification phenomena involve purely morphological or syntactic factors as well, as convincingly argued by Mikami (1970), Harada (1976), and many others. 
mechanism of honorification, and then at approaches that do so. Lastly, we comment on the assumptions of the present paper, whereby suru and naru do not directly contribute to honorification, as well as look at other approaches to the structure of nominal expressions.

\subsection{Honorification and Nominalization}

Harada (1976) and Kuno (1989) are two important contrasting approaches to honorification. Kuno claims that, in an example like the one below, the verb kaeru 'return' is nominalized through the non-finite renyookei form, and that the full verb naru 'become' is used. ${ }^{3}$
(5)

$\begin{array}{lll}\text { Sensei-ga } & \text { o-kaeri-ni } & \text { narimashita. } \\ \text { Professor-Nom } & \text { Hon-go home-Dat } & \text { became }\end{array}$

'The Professor went home.'

The main argument for this claim is that o-kaeri is followed by the Dative case particle $n i$. The fact that a constituent takes case is frequently used as a test for nounhood, and Kuno uses this argument in his claim.

On the other hand, Harada (1976) brings evidence to the effect that the prefix-bearing main verb, like o-kaeri in the example above, cannot occur away from naru.

(6) Yamada sensei-ga o-kaeri-ni natta. *Tanaka
Professor Yamada-Nom go home-Dat became Professor
sensei-mo nat-ta.
Tanaka also became
'Professor Yamada went home. Professor Tanaka did, too.'

(6) shows that ellipsis of the main verb makes the structure ungrammatical. Harada claims that they must form a single constituent, and he provides a structure quite similar to a complex verb structure and offers a set of transformational rules to derive such a structure. Kuno's proposals suggest an important direction in the analysis of honorification in the nominal domain, but Harada's data must also be accounted for in the nominalization analysis. Solving this apparent paradox is necessary for any attempt to provide a unified analysis for Japanese honorification in the nominal and clausal domains.

3 The nominalization analysis is also proposed by Suzuki (1989), who sees verb honorification as similar to noun honorification. 


\subsection{Honorification as Agreement}

Another important line of reasoning has been mentioned in the literature, beginning with Mikami (1970). Mikami claims that the o- suru/ni naru honorific construction is in fact quite similar to subject-predicate and objectpredicate agreement in languages such as Hungarian. Mikami does not offer any arguments for this claim, but studies like Toribio (1990), Kishimoto (1996), Hasegawa (2005) and Boeckx and Niinuma (2004) do.

Toribio (1990) assumes that suru is a control verb and that naru is a raising verb, and she treats honorification as a form of Spec-Head agreement within the raising and control structures, more exactly within a DP headed by the nominalized main verb. She thus gives a unified account for the selection of the target of honorification, which neither Harada nor Kuno had done in a satisfactory manner. She also attempts to explain the subject honorification and the object honorification structures, and claims that honorification takes place within the nominalized clause of the main verb, and thus has no direct connection with suru and naru. Hasegawa (2005) extends Toribio's analysis, claiming that the so-called honorific prefix $o$ - is actually an instance of the functional category D. Unfortunately, those accounts cannot explain Harada's data either, because the suru/naru verbs considered there should be able to exist away from the main verb. Moreover, if Toribio's and Hasegawa's theories are on the right track, honorification takes place within the DP. This would predict that honorification should also occur within pure nominals. However, neither of them makes any mention of purely nominal expressions, and thus an analysis that does not rely on the existence of the main verb is not offered.

In a different approach, Boeckx and Niinuma (2004) adopt the Agree mechanism proposed in Chomsky (2000) in an attempt to explain examples (7) through (9).

(7) Watashi-wa sensei-ni Taroo-wo go-shookai shita.

I-Top Professor-Dat Taroo-Acc Hon-introduction did 'I introduced Taroo to the Professor.'

(8) *Watashi-wa Taroo-ni sensei-wo go-shookai shita.

I-Top Taroo-Dat Professor-Acc Hon-introduction did 'I introduced the Professor to Taroo.'

(9) Watashi-wa sensei-wo o-machi shita.

I-Top Professor-Acc Hon-wait did

'I waited for the Professor'

In the double object constructions in (7) and (8) only the indirect object can be the target of honorification, although in the usual single object structure 
in (9) the direct object can be, too. In order to explain this fact, Boeckx and Niinuma (2004) propose that honorification is in fact a form of agreement between the verb and the closest argument, as shown in (10).

(10)

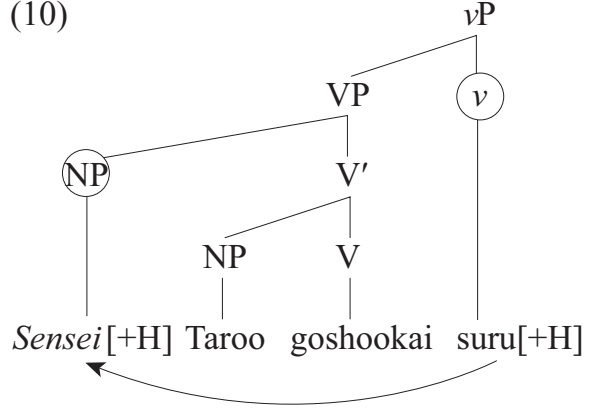

Following Chomsky (2000), Boeckx and Niinuma assume that the argument DPs do not move for agreement. ${ }^{4}$ They argue that the light verb $v$ can only agree with the closest argument of the main verb, which is the indirect object in the case of double object constructions. Thus, if the indirect object is a respected person then honorification takes place and a natural sentence like (7) is formed. If sensei and Taroo are reversed, as in (8), sensei cannot trigger honorification and the sentence would be unnatural, i.e. Taroo would be the respected person. The indirect object effectively blocks honorification/agreement with the lower argument.

We could summarise these observations into a generalization like (11).

(11) A verb agrees in honorification with the target of honorification iff

a) the target is a respected character, i.e. bears an honorific feature, and

b) the target is structurally the closest NP to the verb, i.e. there is no other noun higher up in the structure, within the ccommand domain of the verb.

Boeckx and Niinuma further argue that the phenomena captured by the generalization (11) can be regarded as evidence for Chomsky's (2000) Agree mechanism. ${ }^{5}$ Although their generalization (11) captures an important aspect of honorification phenomena in Japanese, Boeckx and Niinuma have nothing

${ }^{4}$ Boeckx and Niinuma do not provide a detailed structure like the one in (10), and the light verb construction presented here is an assumption on our part. However, their account does not come in contradiction with this assumption.

${ }^{5}$ See Bobaljik and Yatsushiro (2006) for a critical assesment of their argument. 
to say about nominal honorific constructions since they crucially assume that the verb licenses honorification by agreeing with its target. Moreover, few of the previous studies mentioned above treat the prefix $o$ - in any detail, apparently assuming that it is not essential to the derivation, and none of the studies presented above explain in a satisfactory manner why there have to be two verbs, suru and naru, which have to be used according to the grammatical function of the target of honorification.

\subsection{Honorific Verbs are Light Verbs}

Ivana and Sakai (2007) claim that the verbs suru and naru, which appear in the o- suru/ni naru honorific construction, are in fact light verbs in the sense of Grimshaw and Mester (1988) and Sakai et al. (2004), and that the main verb is nominalized by the renyookei form, as claimed by Kuno (1989) and Toribio (1990). Under these assumptions, Harada's data are finally accounted for, because light verbs in general cannot occur away from their arguments (Saito and Hoshi (2000)), as illustrated below.

(12) Kaigi-ga enchoo-ni natta. *Kyuukei-mo natta
meeting-Nom extension-Dat became recess also became
'The meeting was extended. So was the recess.'
(13) Kaigi-wo enchoo shita. *Kyuukei-mo shita
meeting-Acc extension did recess also did
'They extended the meeting. They extended the recess, too.'

Moreover, under this hypothesis the occurrence of the case particle only with naru can be explained by the fact that light verb naru cannot assign case, and therefore the nominalized main verb must be assigned oblique case. This account also makes some pragmatic and structural considerations, to the effect that the differences between the pattern of theta role assignment of suru and naru are directly connected to the differences between subject honorification and object honorification. However, this paper has little to say about the actual mechanism of honorification within pure nominals, the way that Toribio (1990) or Boeckx and Niinuma (2004) do. This matter is the central point of the present paper.

Lastly, Ivana and Sakai also claim that the $o$ - prefix is in fact a functional category $\mathrm{H}$ denoting honorification, which selects a nominalized clause, and that honorification takes place within its domain, thus leaving suru and naru out of direct honorification assignment. In the present paper we test the possibility that the prefix can also select a pure noun, and thus unify the analysis of nominalized verbs and nouns. The sentence structure based on this account is given in (14). 
(14)

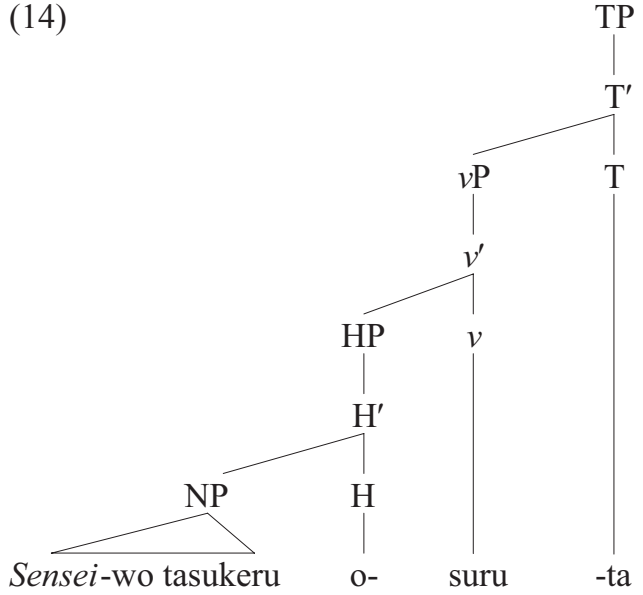

In the present paper we also adopt the functional status of the prefix $o-$. The prefix $o$ - is subsequently attached to the nominalized verb tasukeru at PF. ${ }^{6}$

\section{Beautification and Honorification}

In this section we point out the differences between honorific nominal expressions and another kind of expression with the prefix $o$-/go-, which is called beautification expressions in literature (Shibatani (1990)). We show that the essential difference between these is that beautification expressions, although used in polite conversation, do not express honorification. Furthermore, we show that they are structurally different, and in subsequent sections concentrate upon honorifics only.

The account of Boeckx and Niinuma (2004) works for honorification in full sentences, but in examples like (15) and (16) below the honorification meaning is present, although the expressions are not full sentences.
(15) sensei-no o-kuruma
Professor-Gen Hon-car
'the Professor's car'

${ }^{6}$ The PF morphological operation can be characterized by Morphological Merger (Marantz (1988)) or Affix Hopping (Embick and Noyer (2001)). Either of the operations is arugued to apply after the syntax and is governed by the linear adjacency condition. 


$$
\begin{array}{cl}
\text { (16) *watashi-no } & \text { o-kuruma } \\
\text { I-Gen } & \text { Hon-car } \\
\text { 'my car' } &
\end{array}
$$

The fact that honorification is present in these noun phrases is supported by the contrast between (15) and (16). This situation is parallel to the normal use of honorific constructions as seen below.
(17) Sensei-ga o-kaeri-ni narimashita.
Professor-Nom Hon-go home-Dat became
'The professor has gone home.'
(18) *Watashi-ga o-kaeri-ni narimashita. I-Nom Hon-go home-Dat became
'I went home.'

Boeckx and Niinuma claim that it is the so-called honorific verb which agrees with the target of honorification, but in examples (15) and (16) no verb is present at all, and no verb could even be inferred. We therefore have to look elsewhere for honorification agreement, if we are to support the idea at all.

This means that we must accept agreement inside noun phrases as well as verb phrases. NP internal agreement is present in Romance languages, for instance Romanian, between the noun and its adjectives as well as between the noun and the determiner, as in the examples below.
(19) Fete frumoase
girl-FEM-PL-Nom beautiful-FEM-PL-Nom 'beautiful girls'
(20) acele fete those-FEM-PL-Nom girls-FEM-PL-Nom 'those girls'
(Romanian)
(Romanian)

In Romanian nouns must agree in gender, number and case with their determiners and adjectives. NP internal agreement is also present in English, between the noun and the determiner, which must agree in number, as in the example below.

(21) those/*that girls

It is therefore not unlikely that a similar situation might be possible in Japanese, in terms of honorification agreement.

However, there are many noun phrases in Japanese that contain the honorific prefix, but do not convey the honorification meaning, and they are used in a variety of situations where such meaning would be unnecessary and inappropriate. Examples of these noun phrases are given below. 
(22)

$$
\begin{array}{lll}
\text { o-niku / } & \text { o-cha / } & \text { o-kashi } \\
\text { Hon-meat } & \text { Hon-tea } & \text { Hon-cake } \\
\text { 'meat' } & \text { 'tea' } & \text { 'sweets' }
\end{array}
$$

Such noun phrases are known as bikago, or beautification words. They have pragmatic and lexical properties that differentiate them from honorifics, but there is also an important syntactic difference between them.

In beautification expressions the prefix affects the word it is attached to, like a derivational affix. It is thus similar to English prefixes like un-, in words like uncertain, which supplies an adjective with negative meaning. On the other hand, in honorifics like (15), the prefix affects a different word than the one it is attached to, i.e. o- is attached to kuruma, but respect is shown for sensei. In this respect it is similar to agreement affixes in English, such as the third person singular $-s$, which is attached to the verb, but is required by the subject. Thus, we might say that honorifics have a syntactic structure, because one part of a word affects a separate word, while beautification words do not, because the effect of the prefix does not extend beyond the target word. The structure of honorifics is detailed in the following section.

\section{Honorification in the Nominal Domain}

In this section we look at the syntactic structure of nominal honorific expressions. We propose a pattern of honorific agreement similar to that proposed for verbs by Boeckx and Niinuma (2004). Along the way we propose the notion of light noun, and we look in some detail at the internal structure of some Japanese noun phrases.

\subsection{Honorific Agreement within Noun Phrases}

We have assumed in the previous sections that the honorific prefix $o$-/gois the honorific marker, and therefore it would seem a good candidate for triggering honorification agreement. This idea is supported by the fact that sentences with a respected subject are perfectly acceptable without honorification.

(23) Sensei-ga kaerimashita.

Professor-Nom went home

'The Professor went home.'

Example (23) shows that although an argument denoting a potentially respected person is present, honorification can be absent. Thus, it is not the presence of such an argument that triggers honorification. 
We therefore assume that honorification is triggered by the presence of the honorification marker $o$-. The use of this marker is pragmatically determined by the speaker if it is necessary in the given situation. We follow here Hasegawa (2005) and Ivana and Sakai (2007) and consider the prefix a functional category expressing honorification. We assume an honorification rule (24), similar to the generalization given in (11), except that the prefix rather than the verb plays a role in the honorific agreement.

(24) The honorific prefix agrees in honorification with the target of honorification iff

a) the target is a respected character, i.e. bears an honorific feature, and

b) the target is structurally the closest NP to the prefix, i.e. there is no other noun higher up in the structure, within the c-command domain of the prefix.

(25) illustrates the case of examples like (15), the genitive construction.

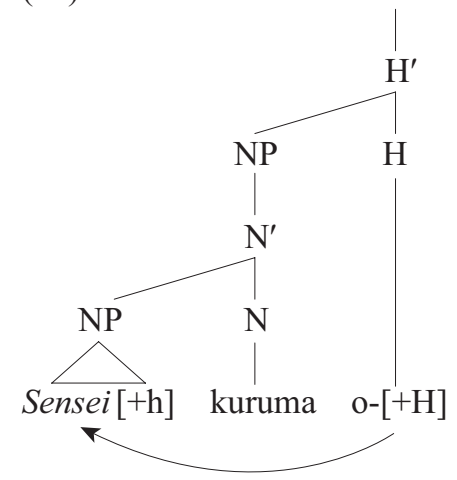

Putting an apparent problem of locality between $o$ - and sensei aside, let us first examine the licensing mechanism of honorific features in this structure. The honorific morpheme agrees with the respected NP sensei. Following Chomsky (1995), we assume that agreement should involve interpretable and uninterpretable features. We therefore propose that sensei has the intrinsic [+honorific] $([+\mathrm{h}]$, henceforth) feature, which agrees with the $[+$ Honorific $]([+\mathrm{H}]$, henceforth) feature of $o-$. This agreement between the $[+\mathrm{h}]$ and $[+\mathrm{H}]$ features is the formal counterpart of the pragmatic knowledge that it is sensei who is respected, and not the car, although the honorific prefix is attached to kuruma.

Here we have to underscore the difference between (14), representing the structure assumed for a full sentence, and (25), proposed here as the struc- 
ture for a noun phrase. In (14) the honorific prefix selects a nominalized clause as its argument, while in (25) it selects a pure noun. This is one of the claims that this paper attempts to demonstrate. (24) and (25) thus represent the basic scheme of our analysis, but in this form it has two major problems. First, example (23) cannot be explained if the honorific features of sensei and the prefix are both formal, because formal features must be checked and there is no way to do so in (23). Second, if agreement occurs between the honorific prefix and the closest noun, the noun kuruma should block agreement with sensei, which is lower in the structure.

Returning to example (23), there is no constituent other than sensei in the sentence that might bear an honorific feature. In order to explain why (23) is possible, we propose that the $[+\mathrm{h}]$ feature of sensei is interpretable and it may or may not be checked, while the $[+\mathrm{H}]$ feature of the $o$ - prefix is uninterpretable and it must be always checked in order for the derivation to converge. ${ }^{7}$ As for the interpretable feature $[+\mathrm{h}]$, it should be noted that the noun phrase itself does not always have this feature as its intrinsic property. The examples below illustrate the fact that the same person may or may not be respected.

$\begin{array}{ll}\text { Tanaka-san-ga o-kaeri-ni } & \text { narimashita. } \\ \text { Mr Tanaka-Nom Hon-go home-Dat } & \text { became } \\ \text { 'Mr Tanaka has left.' } & \\ \text { Tanaka-kun-ga kaetta. } & \\ \text { Tanaka-Nom went home } & \\ \text { 'Tanaka has left.' } & \end{array}$

Example (26) shows respect toward Mr Tanaka, and it may have been uttered by a younger colleague or a subordinate. However, a sentence like (27) can be uttered about the same person, but this time by that person's superior or teacher. These examples show that the $[ \pm \mathrm{h}]$ feature is not intrinsic to the person, or to the word denoting that person, but rather assigned by the speaker. ${ }^{8}$ Note that the difference in honorification occurs together

7 Chomsky $(1995,2000)$ proposes that uninterpretable features make the derivation crash at LF. However, feature checking deletes, or makes invisible, these features at LF. Thus, in a valid derivation uninterpretable features must be checked. On the other hand, Chomsky proposes that interpretable features may exist at LF. Therefore, if the [+honorific] feature of sensei is interpretable, being a reflection of the pragmatic knowledge that a professor is respected, it may exist unchecked within a valid derivation.

8 The [+honorific] feature on words like sensei appears to be intrinsic to the word. A possible solution to this contradiction is discussed in Section 4.2. 
with a change in the appellative suffix attached to the name. In the following sub-section we look in some detail at this matter.

The assumption that interpretable lexical features may remain unchecked has solved our first problem, the existence of respected nouns in non-honorific sentences. In the following sub-section we propose a solution for the second problem, concerning the nouns that can intervene between the honorific projection and the target of honorification.

\subsection{Appellative Suffixes as a Functional Category}

As we have seen in the previous section, a difference in the appellative used can cause a difference in honorification. In Japanese, appellative suffixes are quite numerous and used extensively, in formal as well as in informal situations, even within the family. ${ }^{9}$ In fact, there are very few contexts in which they may not be used, such as a roll call or in the military. Despite being numerous, these appellatives form a closed set. There is a way, however, to extend this set by using words with intrinsic honorific meaning as appellatives, and we shall look at it later in this section. Furthermore, appellatives cannot be used as independent words, but can only exist attached to a human-denoting noun. Summing up the properties of appellatives, they are a closed set, select [+human] targets, and can only be used attached to such targets. These properties are very similar to other functional categories. For instance, the light verb $v$ forms a closed set, selects verbs, and can only be used attached to verbs. ${ }^{10}$

9 There are basically three kinds of appellatives, classified in terms of the honorific meaning they add to the noun they are attached to. First, there are exalting appellatives, such as san, sama, dono. These differ in the degree of respect shown to the character they denote, as well as the context of use. Second, there are the endearing/humbling appellatives such as chan and kun, which are typically used towards intimates and persons younger or of lower rank, for instance in corporate/school hierarchies, than the speaker. Appellatives of the third kind are neutral, such as shi, and are typically used in situations where the rank/social status of the target is unknown, or neutrality is required, such as in newscasts.

10 Another important property of the light verb $v$ is that it determines the categorical status of the root selected as its complement as originally pointed out by Marantz (1997). This seems to apply also to the Japanese light noun $n$, since it determines the [+-human] status of its complement nouns. The typical instance can be seen in nouns denoting non-human animate objects. For instance, the noun neko 'cat' can be used as [-human] in its bare form but used as if it were [+human] with an allelative -chan in neko-chan. Although this property appears to be purely syntactic in the case of $v$ and rather semantic in the case of $n$, we still find this to be an interesting similarity. We thank an anonymous $E L$ reviewer for raising this point. 
We shall therefore call this functional category a light noun $n$, and propose that human denoting nouns all have the structure in (28). The purpose of the light noun is specifically to attach this honorific feature to [+human] nouns, in the same way as the Numeral projection attaches plural features to nouns in European languages.

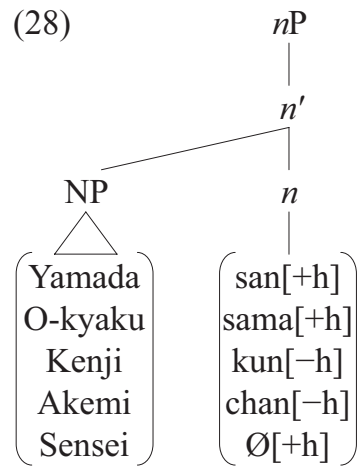

Using this concept, we can now adjust (25) as in (29), and rule (24) as in (30).

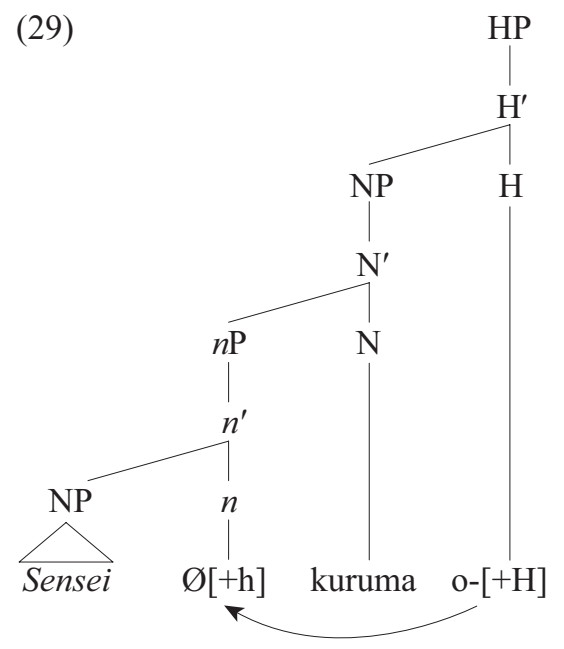

(30) The honorific prefix bearing a feature $[+\mathrm{H}]$ agrees with the target iff

a) the target bears a $[+\mathrm{h}]$ feature, and

b) the target is structurally the closest $\boldsymbol{n} \mathbf{P}$ to the prefix, i.e. there is no other light noun higher up in the structure, within the c-command domain of the prefix. 
This formulation allows for a usual non-human noun like kuruma to exist between the prefix and the target of honorification.

The light noun is not specific to Japanese. In English, for instance, there are appellatives like Mister or Miss, which are used with the same honorific meaning as san or dono in Japanese, though they are fewer in number compared to Japanese. In Japanese the class of appellatives can be extended with appellatives derived from the names of hierarchical or social positions, such as sensei 'professor,' shachoo 'company president,' or hakase 'Doctor.' These words can be used both in their original sense, to designate the respective notions, or they can be used as appellatives, in which case their purpose is to express consideration for their targets. We consider these appellatives to be related but basically different from their fully lexical counterparts, in that they lose their informative character, i.e. the social position of the target is already known to the speaker and the hearer when these are used as appellatives, and acquire/retain only their honorific meaning. ${ }^{11}$

A somewhat similar phenomenon happens with the word Doctor in English. When used as an appellative, together with the name of the person, it shows honorification, while when used as a common noun it does not, as illustrated in the sentences below.

(31) Dr Fleming has discovered penicillin.

(32) A doctor by the name of Fleming has discovered penicillin. In English the presence of the $[ \pm \mathrm{h}]$ feature does not have a syntactic effect, and therefore it may be of a lesser significance than in Japanese, where this feature appears to be directly involved in honorification agreement. In languages like Romanian, where one type of honorification is expressed as a plural conjugation on verbs with singular second person respected subjects, this feature might be of comparable importance to the Japanese one.

At this point we have laid out the essential points of our proposal. First, honorification is achieved by agreement between the honorific functional head realised as the honorific prefix $o-/ g o-$, and a noun bearing a $[+\mathrm{h}]$ feature. Second, the honorific feature is in principle attached to human-denoting nouns by the use of appellatives, which are in fact a functional category

11 An alternative possibility is that appelatives like sensei and shachoo are themselves light nouns, and in cases where these words are used without the name of the person, this name is in fact elided and undestood from the extralinguistic context. Thus, the structure in (28) would look like (i), with the pro interpreted from the context.

(i) [HP [NP pro] sensei]

This analysis would explain the fact that their [+honorific] feature is intrinsic to the word. 
that we call light noun.

\subsection{Implied Target of Honorification}

In the previous section, we presented the basic elements of our analysis of honorification. There are, however, certain expressions that require a more detailed analysis than the basic one proposed above, and we look at one of them in this section. We aim to show that our basic analysis is correct because it can explain these apparently problematic expressions with minimal adjustments.

Let us look at an expression like ojoosama 'young lady.' Ojoosama has three different usages, illustrated in the examples below, whose meanings depend mainly on the addressee of each of the utterances.

Ojoosama-wa moo o-kaeri-desu-ka.

Young lady-Top already Hon-go home-is-Q

'Is the young lady already leaving?'

(34) Sensei-no ojoosama-wa moo o-kaeri-desu-ka.

Professor-Gen young lady-Top already Hon-go home-is-Q

'Has the Professor's daughter already gone home?'

(35) Mayumi-wa seken-wo shiranai ojoosama-da.

Mayumi-Top world-Acc know-Neg young lady-is

'Mayumi is a naive/inexperienced girl.'

In example (33) ojoosama can express consideration for the young lady herself, if the utterance is addressed to her, or it can express consideration towards her parent if the utterance is addressed to the parent or to a third party. In example (34), consideration is shown to sensei, and not to the young lady. This sentence can be uttered towards a third party or towards the professor, but not towards the young lady herself. In example (35) no honorific meaning is present, and the word ojoosama itself can even acquire ironic or derogatory overtones, in a similar manner with the word princess in English, when it is used to designate a spoiled girl. Under these circumstances, it appears that ojoosama used in (33) and (34) is not just a word or a bikago, but has an internal structure that is capable of changing the target of honorification. On the other hand, in example (35) it appears to have been transformed into a normal common noun. Indeed it can be replaced with musume 'girl' without any modification in the meaning of the sentence.

We shall first assume that the suffix -sama is a light noun, as discussed in the preceding section. If that is the case, ojoosama would have the general light noun structure. This structure is given in (36). 
(36)

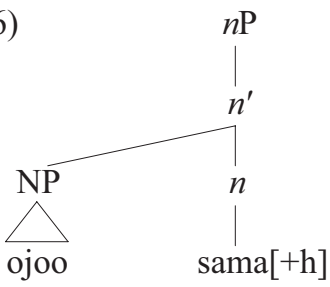

Let us now take a close look at expressions used in (34), repeated in (37) below.

$$
\begin{aligned}
& \text { sensei-no ojoosama } \\
& \text { Professor Gen young lady } \\
& \text { 'the Professor's daughter' }
\end{aligned}
$$

This expression, by itself, can only express consideration towards sensei, and not towards the daughter. ${ }^{12}$

If our reasoning is on the right track, the honorific agreement should take place between the prefix $o$ - and sensei in (37) under the rule (30). If we take a closer look at (37), we can notice that there is one $o$ - prefix present, attached to -joo-, but it is not in the appropriate c-command position. Up to this point we have implicitly assumed that this prefix was fused to -joo-, and thus did not have a role in the syntax of the whole expression. It appears, however, that this is not the case, and that we have to consider its effects in the structure. To do so we assign the structure in (38) to senseino ojoosama.

12 Indeed, it cannot be used towards the daughter herself in ordinary conversation. In Japanese constituents are normally elided unless they are absolutely necessary for the understanding of the sentence. On the other hand, when addressing an expression like (34) to the daughter, it is not necessary to explicitly mention her parent, because she knows who he is. Thus, if the parent is nevertheless mentioned, a specific conversational implicature, for instance ironical connotation, arises since it forces the hearers to pay special attention toward the parenthood relationship. We thank an anonymous $E L$ reviewer for this suggestion. 


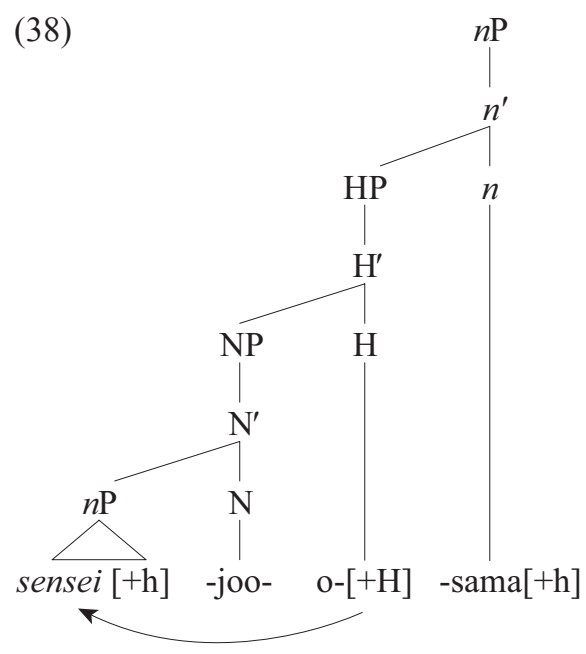

In (38), the target of honorification, sensei, is in the correct position in relation to the prefix $o^{-}$. We assume that this is in fact an $n \mathrm{P}$, and that it refers to some person that has to be respected and has to be inferable either from the discourse or from extra-linguistic clues. The reading of example (33) is obtained when $o$ - agrees with -joo-sama itself, and for this case we propose the alternative structure in (39).

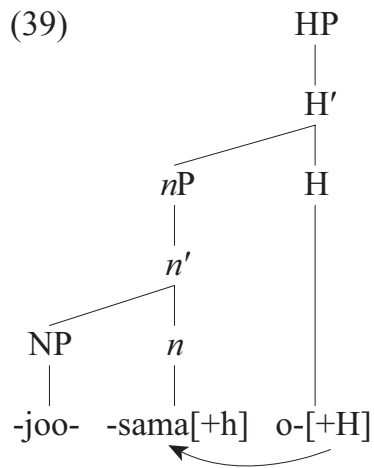

This structure differs from the one in (38) in that the light noun is now within the c-command domain of the honorific prefix.

5. Functional Categories within Japanese Noun Phrases and Its Implications

We are now able to offer a general structure for the Japanese noun phrase 
given in (40) below. The structure contains multiple layers of functional projections, HP and $n \mathrm{P}$, above the NP projection. ${ }^{13}$

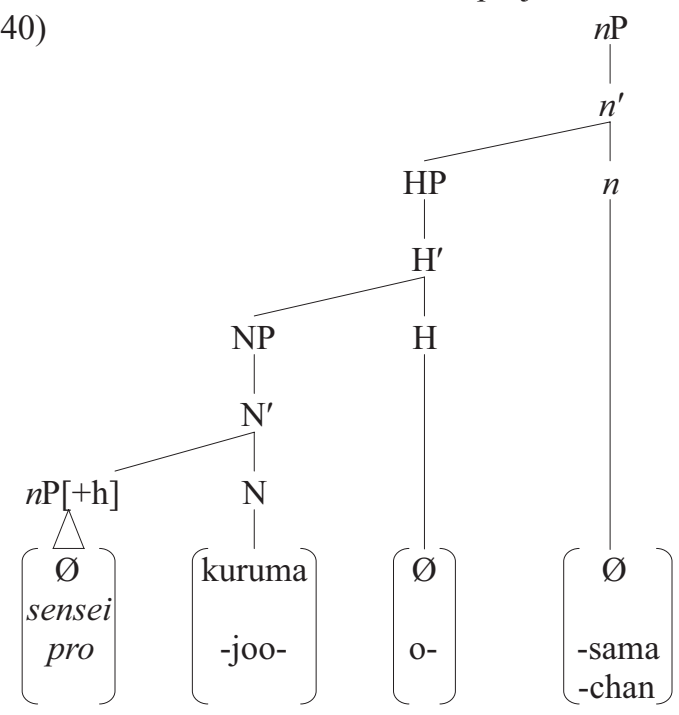

The Japanese noun phrase has a complex internal structure, similar to that proposed by analyses of quantifier phenomena such as Kawashima (1998) and Watanabe $(2006,2008)$, which extend the original DP hypothesis of Abney (1987). ${ }^{14}$ At the same time, the categories proposed in this paper, the light noun $n$ and the honorific prefix $\mathrm{H}$, are quite different from the functional category D found in European languages, because the former have specific semantic and pragmatic content, while the latter typically lacks such content. Our proposal is thus in line with Fukui $(1986,1995)$ and Hoji (1998), who argue that there is no D in Japanese. Although the Japanese

13 If the noun phrase only contains an inanimate or non-respected head noun, the $n$ and $\mathrm{H}$ projections are absent, and the structure is reduced to that of a normal noun phrase.

14 Kawashima (1998) deals with quantifier shift and quantifier float phenomena in Japanese, and she argues for a structure whereby a Numeral functional head is the complement of a Determiner head and selects the noun as its complement. Watanabe (2006, 2008) deals with the same phenomena involving quantifiers, and proposes an even more complex structure than Kawashima's, which includes a projection for Case, directly above the Numeral and below the Quantifier projection. For reasons of space, we cannot demonstrate here the interaction of our proposals with quantifier phenomena, but in principle, our light noun and honorific projections exist immediately above the noun, and below any other functional categories of the noun phrase, and as such do not have any effect on the quantifier phenomena. 
noun phrase has intricate phrase architecture with multiple layers of projections, they do not involve projections of pure functional categories such as D. This is our answer for the apparent paradox pointed out in section 1 .

Another important implication of the analysis presented in this paper is that the features with clear semantic or pragmatic contents can enter into the computation of the Agree mechanism. This is quite different from the typical instance of agreement phenomena in European languages. If the analysis proposed here is on the right track, the features that enter into the computation of the Agree mechanism should be parametrized. That is, in European languages only purely formal features can do so, while in typologically different languages in the world, such as Japanese, semantic or pragmatic features can be involved in their syntactic computation. The proposed analysis of honorification phenomena within nominal domain thus leads us to reconsideration of functional parametrization hypothesis. That is, although the original functional parametrization hypothesis 'restricts' the possible domain of parametrization within the domain of formal features of functional categories (Chomsky (1995: 6)), we should consider that languages can differ as to whether only formal features of functional categories play a role in their syntactic computation or even semantic or pragmatic features can enter into such computation. ${ }^{15}$

\section{Conclusion}

Although extensive research was conducted on honorific constructions in the verbal domain in Japanese, honorification in the nominal domain has never attracted enough attention. In this paper, we dealt with three problems that a unified analysis of Japanese nominal honorific expressions face, and showed that these questions can be answered by the general theory of feature-checking coupled with a hypothesis of rich internal architecture of noun phrases. The prefix 0 -/go- is assumed to be the head of projections and agrees in terms of honorification features with the perceived target of

15 It might be the case that, in typologically related languages within Europe, parameters can be resticted into a narrow domain of purely functional categories. For instance, Longobardi (2001) presents detailed examination of parametric variation among DP structures in European languages and proposes a set of parameters, which are mostly restricted in the domain of functional categories, to account for the typological variation. We thank an anonymous EL reviewer for pointing out the relevance of Longobardi's research of parametric variation in DP structure. 
honorification. The notion of light noun is introduced to designate appellatives such as - san or $-k u n$, which play an essential role as bearers of the lexical honorific feature. It is shown that honorification is not directly dependent upon the presence of verbs in the structure, and that, unlike beautification words, honorific nominal expressions have an internal syntactic structure required for the licensing of syntactic honorific features.

These findings argue for Watanabe's $(2006,2008)$ and Kawashima's (1998) view that the Japanese noun phrases consist of multiple 'NP-shell' projections, and Kishimoto's (1996) and Boeckx and Niinuma's (2004) view that feature-checking is relevant to the determination of the target of honorification. At the same time, neither the syntactic categories which project to form the NP-shell structures nor the features which enter into the checking processes are 'functional' according to the original definition (Fukui (1986), Abney (1987)). Fukui (1995) further assumes that functional categories can be parametrized because they do not have their own 'meaning' (Fukui (1995: 337)). ${ }^{16}$ The categories $n$ and $\mathrm{H}$, which jointly project the noun phrase structure in Japanese, thus cannot be functional because of their semantic/pragmatic content. A possible solution then is to hypothesize that languages can differ with respect to how categories with semantic or pragmatic content can be integrated into their phrase architecture and syntactic computation. Although a full range of examination of the consequences of this proposal is beyond the scope of this paper, it opens for us a way of rethinking the role of functional categories in the theory of parameters.

\section{REFERENCES}

Abney, Steven (1987) The English Noun Phrase in its Sentential Aspect, Doctoral dissertation, MIT.

Bobaljik, Jonathan and Kazuko Yatsushiro (2006) "Problems with Honorification-asAgreement in Japanese: A Reply to Boeckx \& Niinuma," Natural Language and Linguistic Theory 24, 355-384.

Boeckx, Cedric and Fumikazu Niinuma (2004) "Conditions on Agreement in Japanese," Natural Language and Linguistic Theory 22, 453-480.

${ }^{16}$ Fukui (1995) notes that the term 'meaning' should be characterized precisely. According to Fukui, functional categories, though having their own semantic contribution, are still distinct from lexical categories since they do not serve as 'basic units of thought' for human language. We leave the precise characterization that captures such a distinction for future research. 
Borer, Hagit (1984) Parametric Syntax: Case Studies in Semitic and Romance Languages, Foris, Dordrecht.

Chomsky, Noam (1995) The Minimalist Program, MIT Press, Cambridge, MA.

Chomsky, Noam (2000) "Minimalist Inquiries: The Framework," Step by Step: Essays on Minimalist Syntax in Honor of Howard Lasnik, ed. by Roger Martin, David Michaels and Joan Uriagereka, 89-151, MIT Press, Cambridge, MA.

Embick, David and Rolf Noyer (2001) "Movement Operations after Syntax," Linguistic Inquiry 32, 555-595.

Fukui, Naoki (1986) Theory of Projection in Syntax, Doctoral dissertation, MIT. [Published by CSLI, Stanford, 1995.]

Fukui, Naoki (1995) "The Principles and Parameters Approach: A Comparative Syntax of English and Japanese," Approaches to Language Typology, ed. by Masayoshi Shibatani and Theodora Bynon, 327-372, Clarendon Press, Oxford.

Fukui, Naoki and Hiromu Sakai (2003) "The Visibility Guideline for Functional Categories: Verb Raising in Japanese and Related Issues," Lingua 113, 321-375.

Grimshaw, Jane and Armin Mester (1988) "Light Verbs and Theta Marking," Linguistic Inquiry 19, 205-232.

Harada, Shin'ichi (1976) "Honorifics," Japanese Generative Grammar, Syntax and Semantics 5, ed. by Masayoshi Shibatani, 499-561, Academic Press, New York.

Hasegawa, Nobuko (2005) "Honorifics," The Blackwell Companion to Syntax 2, ed. by Martin Everaert and Henk Van Riemsdijk, 493-543, Blackwell, Oxford.

Hoji, Hajime (1998) "Null Object and Sloppy Identity in Japanese," Linguistic Inquiry 29, 127-152.

Ivana, Adrian and Hiromu Sakai (2007) "Honorification and Light Verbs in Japanese," Journal of East Asian Linguistics 16, 171-191.

Kawashima Ruriko (1998) "The Structure of Extended Nominal Phrases: The Scrambling of Numerals, Approximate Numerals and Quantifiers in Japanese," Journal of East Asian Linguistics 7, 1-26.

Kishimoto, Hideki (1996) "Agr and Agreement in Japanese," Formal approaches to Japanese linguistics 2, MIT Working Papers in Linguistics 29, ed. by Masatoshi Koizumi, Masayuki Oishi and Uli Sauerland, 41-60, Cambridge, MA.

Kishimoto, Hideki (2001) "Binding of Indeterminate Pronouns and Clause Structure in Japanese," Linguistic Inquiry 32, 597-633.

Koizumi, Masatoshi (2000) "String Vacuous Overt Verb Raising," Journal of East Asian Linguistics 9, 227-285.

Kuno, Susumu (1989) "Keigobun no Koozoo (The Structure of Honorific Constructions)," Nihongogaku no Shintenkai (New Directions in Japanese Linguistics), ed. by Kuno Susumu and Shibatani Masayoshi, 103-124, Kurosio, Tokyo.

Longobardi, Giuseppe (2001) "The Structure of DPs: Some Principles, Parameters, and Problems," The Handbook of Contemporary Syntactic Theory, ed. by Mark Baltin and Chris Collins, 562-604, Blackwell, Oxford.

Marantz, Alec (1988) "Clitics, Morphological Merger, and the Mapping to Phonological Structure," Theoretical Morphology: Approaches in Modern Linguistics, ed. by Michael Hammond and Michael Noonan, 253-270, Academic Press, San 
Diego.

Marantz, Alec (1997) "No Escape from Syntax: Don't Try Morphological Analysis in the Privacy of Your Own Lexicon," Proceedings of the 21st Annual Penn Linguistics Colloquium: Penn Working Papers in Linguistics 4, ed. by A. Dimitriadis et al., 201-225, University of Pennsylvania, Philadelphia.

Mikami, Akira (1970) "Keigohoo Naigai (The Honorifics within or outside of Japan)," Bunpoo Shooronshuu (A Collection of Short Papers in Grammar), 88112, Kurosio, Tokyo.

Saito, Mamoru and Hiroto Hoshi (2000) "Japanese Light Verb Construction and the Minimalist Program," Step by Step: Essays on Minimalist Syntax, in Honor of Howard Lasnik, ed. by Roger Martin, David Michaels and Joan Uriagereka, 261-295, MIT Press, Cambridge, MA.

Sakai, Hiromu, Adrian Ivana and Chao Zhang (2004) "The Role of Light Verb Projection in Transitivity Alternation," English Linguistics 21, 348-375.

Shibatani, Masayoshi (1990) The Languages of Japan, Cambridge University Press, Cambridge.

Suzuki, Tatsuya (1989) "A Syntactic Analysis of an Honorific Construction o ...-ni naru," WCCFL 8, 373-383.

Toribio, Almeida J. (1990) "Specifier-Head Agreement in Japanese," WCCFL 9, 535-548.

Watanabe, Akira (2006) "Functional Projections of Nominals in Japanese: Syntax of Classifiers," Natural Language and Linguistic Theory 24, 241-306.

Watanabe, Akira (2008) "The Structure of DP," The Oxford Handbook of Japanese Linguistics, ed. by Shigeru Miyagawa and Mamoru Saito, 513-540, Oxford University Press, Oxford.

[received April 20 2009, accepted July 28 2009]

(Hiromu Sakai)

Graduate School of Education

Hiroshima University

1-1-1 Kagamiyama, Higashi-Hiroshima

Hiroshima 739-8524

e-mail: hsakai@hiroshima-u.ac.jp

(Adrian Ivana)

Bell Forest Morishita 202

2-14-6 Shin Ohashi, Kootoo-ku

Tokyo 135-0007

e-mail: adi729@gmail.com 